Rev. Saúde públ., S.Paulo, 26(4): 295-8, 1992.

\title{
Curvas de sobrevivência de pacientes de AIDS em Santos, Brasil*
}

\section{Survival curves of AIDS patients in Santos, Brazil}

São apresentadas as probabilidades de sobrevivência de pacientes portadores de virus da AIDS residentes no Município de Santos, estimadas a partir do estudo de 1.056 notificações feitas nos anos de 1988, 1989 e 1990. Foram analisadas fichas de investigação epidemiológica, enviadas por serviços ambulatoriais ou obtidas mediante busca ativa realizada rotineiramente nos hospitais do citado Município. As informações sobre óbitos originamse dos cartórios de registro civil de Santos, São Vicente e Guarujá e de notificações rece- bidas. A estimativa de perdas - óbitos registrados em cartórios de outras regiões - é inferior a $2 \%$, proporção de ocorrência na população geral segundo dados da Fundação SEADE. Os pacientes foram agrupados por sexo e por estágio evolutivo da doença, sendo classificados em "casos" (IV B, IV C, IV D e IV E conforme classificação do Center of Disease Control), suspeitos (classe IV A do C.D.C.) e soropositivos assintomáticos (classe I, II e III do C.D.C.)

Tabela 1 - Sobrevida dos casos de AIDS - Homens

\begin{tabular}{lccccccc}
\hline Periodo & $\begin{array}{c}\text { Vivos no } \\
\text { início }\end{array}$ & $\begin{array}{c}\text { Mortos no } \\
\text { período }\end{array}$ & $\begin{array}{c}\text { Retirados } \\
\text { vivos* }\end{array}$ & $\begin{array}{c}\text { Realmente } \\
\text { expostos }\end{array}$ & $\begin{array}{c}\text { Proporção } \\
\text { de mortes }\end{array}$ & $\begin{array}{c}\text { Prop. sobrevida } \\
\text { no perído }\end{array}$ & $\begin{array}{c}\text { Prop. sobrevida } \\
\text { desde o inicio }\end{array}$ \\
\hline$<6$ meses & 143 & 70 & 12 & 137 & 0.5109 & 0.4891 & 0.4891 \\
6.12 meses & 61 & 14 & 9 & 56.5 & 0.2478 & 0.7522 & 0.3679 \\
12.18 meses & 38 & 7 & 10 & 33 & 0.2121 & 0.7879 & 0.2898 \\
18.24 meses & 21 & 5 & 11 & 15.5 & 0.3226 & 0.6774 & 0.1963 \\
$24-30$ meses & 5 & 1 & 2 & 4 & 0.2500 & 0.7500 & 0.1473 \\
$30-36$ meses & 2 & & 2 & 1 & 0.0000 & 1.0000 & 0.1473 \\
\hline
\end{tabular}

* Nāo houve perda

Tabela 2 - Sobrevida dos casos de AIDS - Mulheres

\begin{tabular}{lccccccc}
\hline Periodo & $\begin{array}{c}\text { Vivos no } \\
\text { início }\end{array}$ & $\begin{array}{c}\text { Mortos no } \\
\text { período }\end{array}$ & $\begin{array}{c}\text { Retirados } \\
\text { vivos* }\end{array}$ & $\begin{array}{c}\text { Realmente } \\
\text { expostos }\end{array}$ & $\begin{array}{c}\text { Proporção } \\
\text { de mortes }\end{array}$ & $\begin{array}{c}\text { Prop. sobrevida } \\
\text { no período }\end{array}$ & $\begin{array}{c}\text { Prop. sobrevida } \\
\text { desde o início }\end{array}$ \\
\hline$<6$ meses & 28 & 8 & 7 & 24.5 & 0.3265 & 0.6735 & 0.6735 \\
$6-12$ meses & 13 & 3 & 3 & 11.5 & 0.2609 & 0.7391 & 0.4978 \\
$12-18$ meses & 7 & 2 & 1 & 6.5 & 0.3077 & 0.6923 & 0.3446 \\
$18-24$ meses & 4 & 0 & 2 & 3 & 0.0000 & 1.0000 & 0.3446 \\
$24-30$ meses & 2 & 0 & 2 & 1 & 0.0000 & 1.0000 & 0.3446 \\
30.36 meses & 0 & 0 & 0 & 0 & 0.0000 & 1.0000 & 0.3446 \\
\hline
\end{tabular}

* Não houve perda

\footnotetext{
* Nota apresentada por Cláudio Maierovitch Pessanha Henriques, Tarcísio Soares Borges Filho e Carolina Ozawa Rodrigues do Centro de Controle de Doenças da Secretaria de Higiene e Saúde da Prefeitura Municipal de Santos - Santos, SP - Brasil

Separatas/Reprints: C.M.P. Henriques - R. Dr. Cláudio Lima da Costa, 280 - 11075-100 - Santos - SP - Brasil.

Publicação financiada pela FAPESP. Processo Saúde Coletiva 91/4994-0.
} 


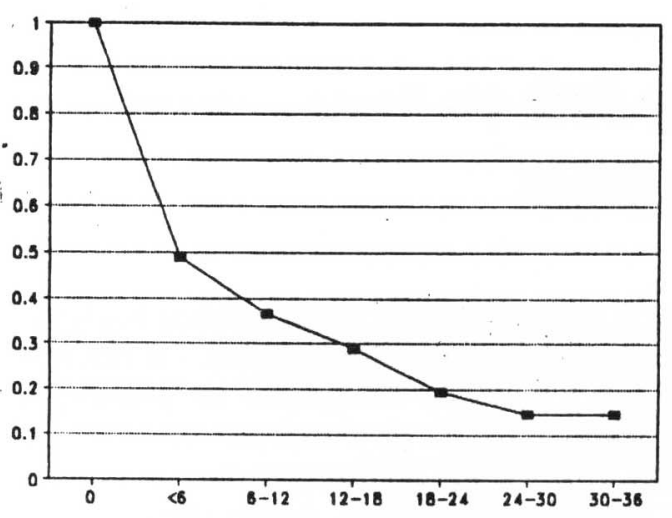

Gráfico 1. Curva de sobrevivência dos casos de AIDS - Homens

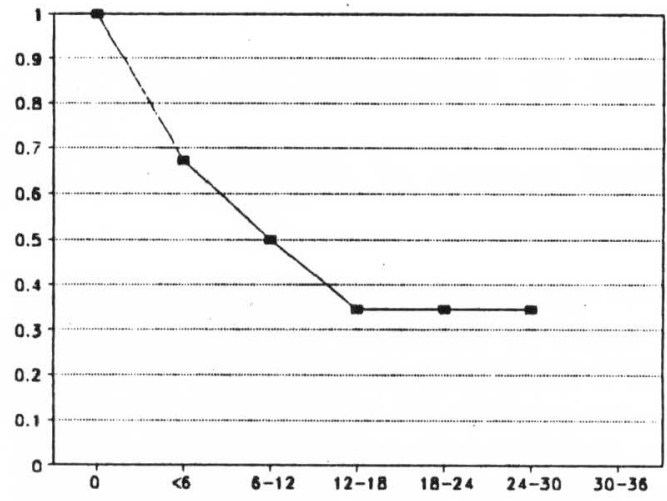

Gráfico 2. Curva de sobrevivência dos casos de AIDS - Mulheres

Tabela 3 - Sobrevida dos casos de AIDS - Total

\begin{tabular}{lccccccc}
\hline & $\begin{array}{c}\text { Vivos no } \\
\text { início }\end{array}$ & $\begin{array}{c}\text { Mortos no } \\
\text { período }\end{array}$ & $\begin{array}{c}\text { Retirados } \\
\text { vivos* }\end{array}$ & $\begin{array}{c}\text { Realmente } \\
\text { expostos }\end{array}$ & $\begin{array}{c}\text { Proporção } \\
\text { de mortes }\end{array}$ & $\begin{array}{c}\text { Prop. sobrevida } \\
\text { no período }\end{array}$ & $\begin{array}{c}\text { Prop. sobrevida } \\
\text { desde o início }\end{array}$ \\
\hline$<6$ meses & 171 & 78 & 19 & 161.5 & 0.4830 & 0.5170 & 0.5170 \\
$6-12$ meses & 74 & 17 & 12 & 68 & 0.2500 & 0.7500 & 0.3878 \\
$12-18$ meses & 45 & 9 & 11 & 39.5 & 0.2278 & 0.7722 & 0.2994 \\
$18-24$ meses & 25 & 5 & 13 & 18.5 & 0.2703 & 0.7297 & 0.2185 \\
$24-30$ meses & 7 & 1 & 4 & 5 & 0.2000 & 0.8000 & 0.1748 \\
$30-36$ meses & 2 & 0 & 2 & 1 & 0.0000 & 1.0000 & 0.1748 \\
\hline
\end{tabular}

* Nāo houve perda

Tabela 4 - Sobrevida de pacientes "suspeitos" de AIDS - Homens

\begin{tabular}{lccccccc}
\hline Periodo & $\begin{array}{c}\text { Vivos no } \\
\text { início }\end{array}$ & $\begin{array}{c}\text { Mortos no } \\
\text { período }\end{array}$ & $\begin{array}{c}\text { Retirados } \\
\text { vivos* }\end{array}$ & $\begin{array}{c}\text { Realmente } \\
\text { expostos }\end{array}$ & $\begin{array}{c}\text { Proporçāo } \\
\text { de mortes }\end{array}$ & $\begin{array}{c}\text { Prop. sobrevida } \\
\text { no período }\end{array}$ & $\begin{array}{c}\text { Prop. sobrevida } \\
\text { desde o início }\end{array}$ \\
\hline$<6$ meses & 138 & 45 & 15 & 130.5 & 0.3448 & 0.6552 & 0.6552 \\
6.12 meses & 78 & 15 & 13 & 71.5 & 0.2098 & 0.7902 & 0.5177 \\
12.18 meses & 50 & 3 & 15 & 42.5 & 0.0706 & 0.9294 & 0.4812 \\
$18-24$ meses & 32 & 1 & 15 & 24.5 & 0.0408 & 0.9592 & 0.4615 \\
$24-30$ meses & 16 & 0 & 11 & 10.5 & 0.0000 & 1.0000 & 0.4615 \\
$30-36$ meses & 5 & 0 & 5 & 2.5 & 0.0000 & 1.0000 & 0.4615 \\
\hline
\end{tabular}

* Näo houve perda

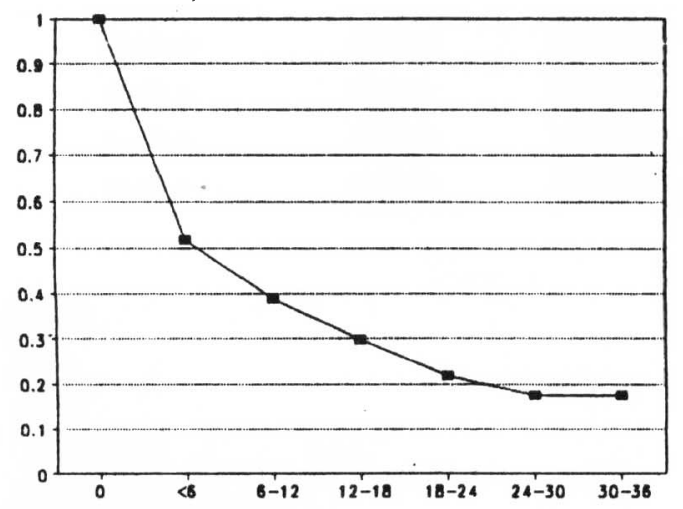

Gráfico 3. Curva de sobrevivência dos casos de AIDS - Total

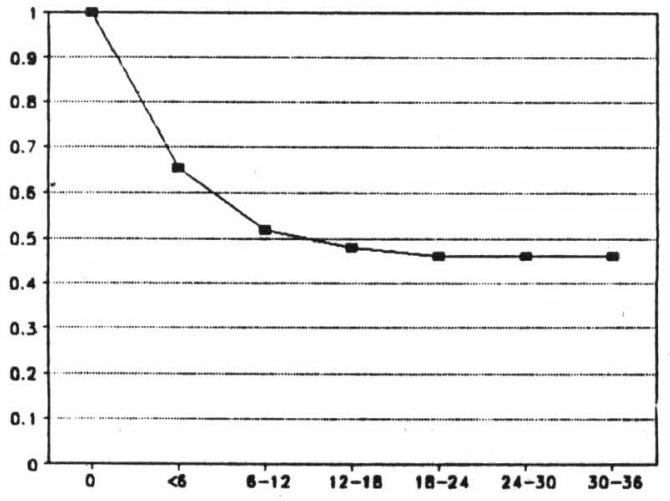

Gráfico 4. Curva de sobrevivência de pacientes "suspeitos" de AIDS - Homens 
Tabela 5 - Sobrevida de pacientes "suspeitos" de AIDS - Mulheres

\begin{tabular}{lccccccc}
\hline Período & $\begin{array}{c}\text { Vivos no } \\
\text { início }\end{array}$ & $\begin{array}{c}\text { Mortos no } \\
\text { periodo }\end{array}$ & $\begin{array}{c}\text { Retirados } \\
\text { vivos }^{*}\end{array}$ & $\begin{array}{c}\text { Realmente } \\
\text { expostos }\end{array}$ & $\begin{array}{c}\text { Proporção } \\
\text { de mortes }\end{array}$ & $\begin{array}{c}\text { Prop. sobrevida } \\
\text { no período }\end{array}$ & $\begin{array}{c}\text { Prop. sobrevida } \\
\text { desde o início }\end{array}$ \\
\hline$<6$ meses & 74 & 16 & 12 & 68 & 0.2353 & 0.7647 & 0.7647 \\
6.12 meses & 46 & 7 & 14 & 39 & 0.1795 & 0.8205 & 0.6275 \\
12.18 meses & 25 & 2 & 7 & 21.5 & 0.0930 & 0.9070 & 0.5691 \\
18.24 meses & 16 & 0 & 7 & 12.5 & 0.0000 & 1.0000 & 0.5691 \\
$24-30$ meses & 9 & 0 & 5 & 6.5 & 0.0000 & 1.0000 & 0.5691 \\
30.36 meses & 4 & 0 & 4 & 2 & 0.0000 & 1.0000 & 0.5691 \\
\hline
\end{tabular}

* Não houve perda

Tabela 6 - Sobrevida de pacientes "suspeitos" de AIDS - Total

\begin{tabular}{lccccccc}
\hline Periodo & $\begin{array}{c}\text { Vivos no } \\
\text { início }\end{array}$ & $\begin{array}{c}\text { Mortos no } \\
\text { período }\end{array}$ & $\begin{array}{c}\text { Retirados } \\
\text { vivos* }\end{array}$ & $\begin{array}{c}\text { Realmente } \\
\text { expostos }\end{array}$ & $\begin{array}{c}\text { Proporção } \\
\text { de mortes }\end{array}$ & $\begin{array}{c}\text { Prop. sobrevida } \\
\text { no periodo }\end{array}$ & $\begin{array}{c}\text { Prop. sobrevida } \\
\text { desde o inicio }\end{array}$ \\
\hline$<6$ meses & 212 & 61 & 27 & 198.5 & 0.3073 & 0.6927 & 0.6927 \\
$6-12$ meses & 124 & 22 & 27 & 110.5 & 0.1991 & 0.8009 & 0.5548 \\
12.18 meses & 75 & 5 & 22 & 64 & 0.0781 & 0.9219 & 0.5114 \\
$18-24$ meses & 48 & 1 & 22 & 37 & 0.0270 & 0.9730 & 0.4976 \\
$24-30$ meses & 25 & 0 & 16 & 17 & 0.0000 & 1.0000 & 0.4976 \\
30.36 meses & 9 & 0 & 9 & 4.5 & 0.0000 & 1.0000 & 0.4976 \\
\hline
\end{tabular}

* Não houve perda

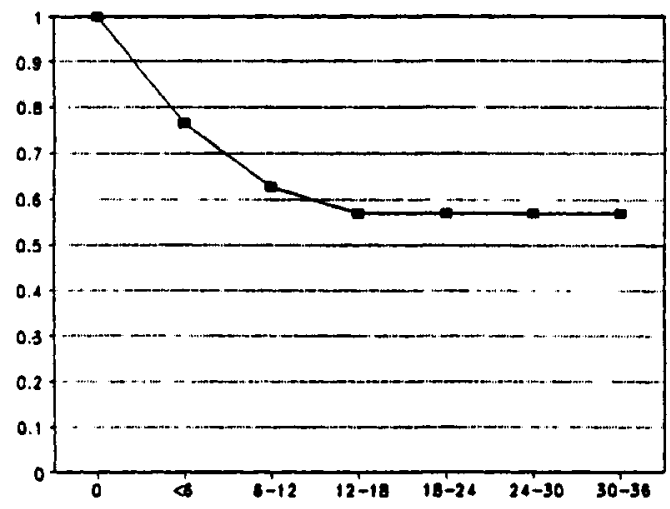

Gráfico 5. Curva de sobrevivência de pacientes "suspeitos" de AIDS - Mulheres

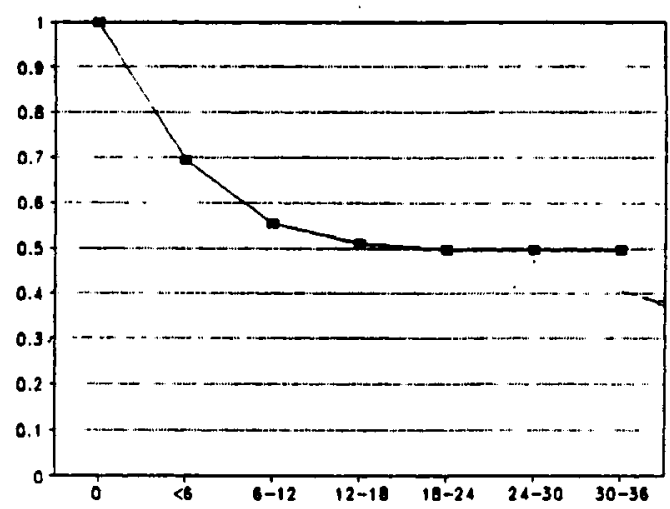

Gráfico 6. Curva de sobrevivência de pacientes "suspeitos" de AIDS - Total

Tabela 7 - Sobrevida de pacientes de AIDS soropositivos assintomáticos - Homens

\begin{tabular}{lccccccc}
\hline Período & $\begin{array}{c}\text { Vivos no } \\
\text { início }\end{array}$ & $\begin{array}{c}\text { Mortos no } \\
\text { período }\end{array}$ & $\begin{array}{c}\text { Retirados } \\
\text { vivos }\end{array}$ & $\begin{array}{c}\text { Realmente } \\
\text { expostos }\end{array}$ & $\begin{array}{c}\text { Proporção } \\
\text { de mortes }\end{array}$ & $\begin{array}{c}\text { Prop. sobrevida } \\
\text { no período }\end{array}$ & $\begin{array}{c}\text { Prop. sobrevida } \\
\text { desde o início }\end{array}$ \\
\hline < 6 meses & 449 & 14 & 73 & 412.5 & 0.0339 & 0.9661 & 0.9661 \\
$6-12$ meses & 362 & 11 & 55 & 334.5 & 0.0329 & 0.9671 & 0.9343 \\
12.18 meses & 296 & 9 & 53 & 269.5 & 0.0334 & 0.9666 & 0.9031 \\
18.24 meses & 234 & 10 & 100 & 184 & 0.0543 & 0.9457 & 0.8540 \\
$24-30$ meses & 124 & 2 & 84 & 82 & 0.0244 & 0.9756 & 0.8332 \\
30.36 meses & 38 & 0 & 38 & 19 & 0.0000 & 1.0000 & 0.8332 \\
\hline
\end{tabular}

- Não houve perda 
Tabela 8 - Sobrevida de pacientes de AIDS soropositivos assintomáticos - Mulheres

\begin{tabular}{lccccccc}
\hline Periodo & $\begin{array}{c}\text { Vivos no } \\
\text { início }\end{array}$ & $\begin{array}{c}\text { Mortos no } \\
\text { período }\end{array}$ & $\begin{array}{c}\text { Petirados } \\
\text { vivos* }\end{array}$ & $\begin{array}{c}\text { Realmente } \\
\text { expostos }\end{array}$ & $\begin{array}{c}\text { Proporção } \\
\text { de mortes }\end{array}$ & $\begin{array}{c}\text { Prop. sobrevida } \\
\text { no período }\end{array}$ & $\begin{array}{c}\text { Prop. sobrevida } \\
\text { desde o início }\end{array}$ \\
\hline$<6$ meses & 224 & 3 & 46 & 201 & 0.0149 & 0.9851 & 0.9851 \\
6.12 meses & 175 & 0 & 42 & 154 & 0.0000 & 1.0000 & 0.9851 \\
12.18 meses & 133 & 4 & 28 & 119 & 0.0336 & 0.9664 & 0.9520 \\
18.24 meses & 101 & 0 & 37 & 82.5 & 0.0000 & 1.0000 & 0.9520 \\
24.30 meses & 64 & 1 & 32 & 48 & 0.208 & 0.9792 & 0.9321 \\
$30-36$ meses & 31 & 1 & 30 & 16 & 0.0625 & 0.9375 & 0.8739 \\
\hline
\end{tabular}

- Não houve perda

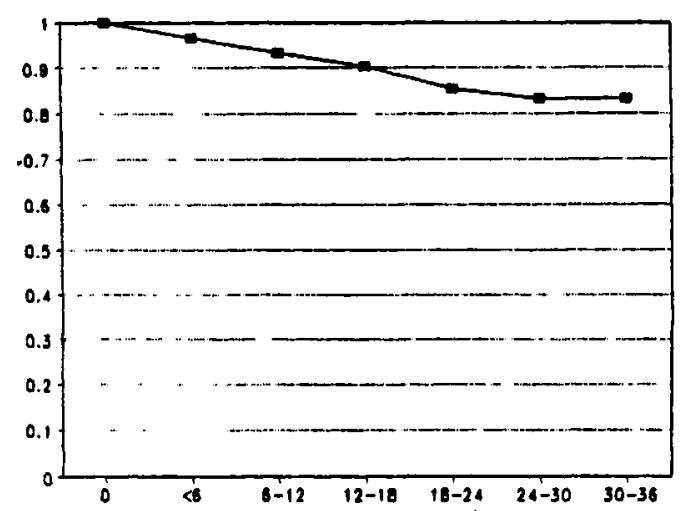

Gráflco 7. Curva de sobrevivência de pacientes de AIDS soropositivos assintomáticos - Homens

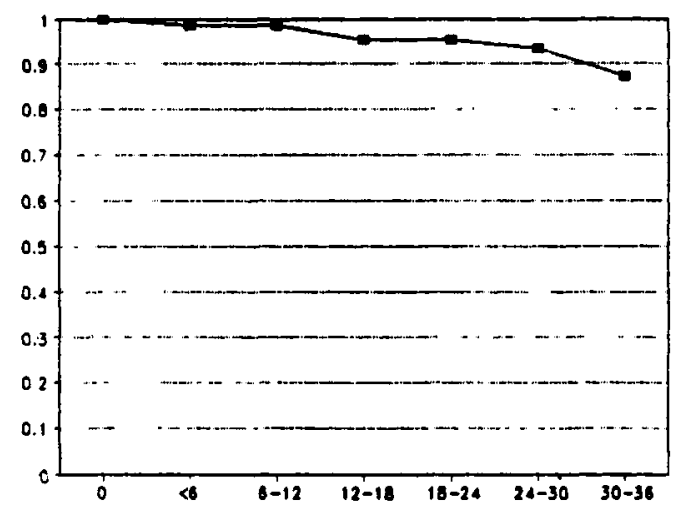

Gráfico 8. Curva de sobrevivencia de pacientes de AIDS soropositivos assintomáticos - Mulheres

Tabela 9 - Sobrevida de pacientes de AIDS soropositivos assintomáticos - Total

\begin{tabular}{lccccccc}
\hline Periodo & $\begin{array}{c}\text { Vivos no } \\
\text { inícjo }\end{array}$ & $\begin{array}{c}\text { Mortos no } \\
\text { periodo }\end{array}$ & $\begin{array}{c}\text { Retirados } \\
\text { vivos* }\end{array}$ & $\begin{array}{c}\text { Realmente } \\
\text { expostos }\end{array}$ & $\begin{array}{c}\text { Proporção } \\
\text { de mortes }\end{array}$ & $\begin{array}{c}\text { Prop. sobrevida } \\
\text { no periodo }\end{array}$ & $\begin{array}{c}\text { Prop. sobrevida } \\
\text { desde o início }\end{array}$ \\
\hline$<6$ meses & 673 & 17 & 119 & 613.5 & 0.0277 & 0.9723 & 0.9723 \\
$6-12$ meses & 537 & 11 & 97 & 488.5 & 0.0225 & 0.9775 & 0.9504 \\
12.18 meses & 429 & 13 & 81 & 388.5 & 0.0335 & 0.9665 & 0.9186 \\
18.24 meses & 335 & 10 & 137 & 266.5 & 0.0375 & 0.9625 & 0.8841 \\
$24-30$ meses & 188 & 3 & 116 & 130 & 0.0231 & 0.9769 & 0.8637 \\
30.36 meses & 69 & 1 & 68 & 35 & 0.0286 & 0.9714 & 0.8390 \\
\hline
\end{tabular}

* Não houve perda

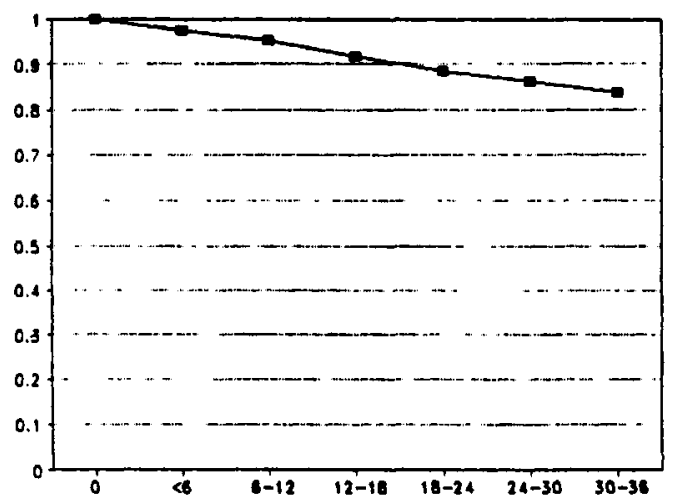

Gráfico 9. Curva de sobrevivência de pacientes de AIDS soropositivos assintomáticos - Total 